\title{
Analysis on the Countermeasure of China's IP Drama Importing to Vietnam under the New Media Environment
}

\author{
Zhijing Zhu* and Guicheng Zhuang \\ School of Humanities, Jianghan University, Wuhan, Hubei 430056, China
}

\begin{abstract}
With the arrival of the new media era and the continuous development of China's domestic IP dramas, the downturn in domestic TV dramas has been broken, more and more IP dramas obtain higher audience rating rely on the Internet, and it becomes a phenomenon hot style. Vietnam is geographically adjacent to China, and they have similar cultures. A lot of Vietnamese culture is derived from Chinese culture, and they are heavily influenced by the values and lifestyle of Confucius in the past, Chinese film and television is a literary genre familiar to Vietnamese, which is one of the most important components of daily entertainment. This paper will research on how to use the Internet to strengthen the import of film and television culture to Vietnam, so that Chinese IP dramas can also increase the audience rating in Vietnam and enhance the cultural export.
\end{abstract}

Film and Television Cultural Communication Power is one of core index to measure the soft power of national film and television culture. The new era of Chinese socialism characteristics has opened up a new development pattern for the dissemination of Chinese film and television culture, "under the guidance of 'One Belt And One Road' construction and 'mass entrepreneurship and innovation' strategic policy”[1], to tell Chinese stories well, let Chinese films and TV shows to "go global", we should expand channels of cultural exchange with other countries continually, and inject new vitality into the development of China's cultural soft power. Chinese films and TV shows have a profound influence on the daily lives of Vietnamese, "Whether it's on TV, online, on CD or in public cinema, including films that have been broadcast and translated with Chinese subtitles, or with Vietnamese subtitles but the original Chinese sound, they all have Chinese culture elements"[2]. Therefore, due to the spread of Chinese films, various ages Vietnamese have generally known and come into contact with Chinese. However, a group of Vietnamese, they have learned and understood Chinese. From a cultural point of view, the degree of cultural discount caused by cultural differences is significantly reduced. Chinese movies and television on international TV, cinema and Internet platforms are underperforming due to limited communication methods and channels. Therefore, it's important to rely on the

\footnotetext{
* Corresponding author: gczhuang@163.com
} 
multimedia environment, and use the interactive integration between the platforms to make up for weaknesses.

\section{The developing status of IP dramas in Vietnam}

\subsection{Summary of background}

The concept of IP drama is widely accepted by the film and television industry, and "it refers to the films and TV series adapted from the purchase of original online novels, games, anime and other works by enterprises with a specific fan base"[3]. These films and TV dramas adapted from original works on the Internet are called IP dramas, "which highlights the protection of intellectual property rights of original works on the Internet by the film and TV industry"[4], and indicates the improvement of the protection awareness of intellectual property rights of media in the new era.

"The rise of IP drama is the result of political, economic, social, technological and other factors"[5]. In terms of national policy, since 2015, "the State Administration of Press, Publication, Radio, Film and Television (SAPPRFT) has introduced the policy of 'one drama, two stars' "[6], which requires no more than two comprehensive channels to broadcast the same TV series during the prime time in the evening, and no more than two prime-time episodes of the same TV series can be aired. A movie or TV series cannot be sold for two satellite channels to operate simultaneously, which indicates that the investment risk of film and television drama rises sharply, and the huge amount of capital is difficult to recover, so the purchase cost of movies and TV dramas rises accordingly, and the uncertainty factors of audience rating become more and more complex. In order to control the production cost, purchasing Internet IP fiction at a low price and adapting it into movies and TV plays has become the response of production teams and TV stations. From an economic point of view, novel based on Internet IP is very popular with the public, because it has a huge fan base, when those novels are adapted to IP dramas, they usually have the advantage of being popular before they are even aired. On the other hand, "IP dramas can also promote the development of related IP industries"[7]. In social terms, audience aesthetic appreciation is gradually improving those days, and "people's demand for high-quality film and television works is much higher than before"[8]. Generally speaking, the way of adapted IP dramas can meet the expectations of more audiences, and the public love for high-quality IP novels has also contributed to the popularity of IP dramas. So, "IP fever" is seen as a trend in the development of the film and television industry. From the technical point of view, The development of Internet technology has contributed to the fragmented behavior of the viewer and the fragmentation of the media, in order to adapt to the different requirements of each audience, major online video platforms make full use of big data technology to research and analyze the IP favored by audiences, and finally use these IP data as the resources of film and television production to attract the audience market.

\subsection{Spreading in Vietnam}

Chinese film and television industry pays more attention to production modes such as IP resource adaptation, international cooperative shooting, genre innovation and integration, and exquisite large-scale production. Investors in Chinese film and television industry often promote the development of certain types to form a trend, they also produce many works following the trend based on the feedback of domestic and foreign audiences to some pioneering works. Costume dramas adapted from online novels, romantic romantic dramas, 
bright youth dramas, and more recently fantasy dramas which is popular in Vietnam. The proportion of previously mainstream core themes is declining, such as historical dramas and social ethics dramas.

For example, in the popular IP series in China, "love TV series adapted from Guo Man's novel of the same name 'The fir is coming' and 'My Sunshine', which are very popular with young audiences in Vietnam"[9]. Another kind of costume IP adaptation, "The Journey of Flower”, “The Biography of Chu Qiao”, “Ten Miles of Peach Blossoms”, no matter what it is plot design, character relationship or picture shooting, role modeling, actor interpretation, they all can capture the hearts of the audience. It is not only that the storyline is compelling, but also that "it has found a new way to open the traditional Chinese culture, the visual images and spiritual inheritance with Oriental artistic conception have made the audience feel the long-lost Chinese imagination". In addition, " 'Yanxi Palace' ” was also the most searched TV series globally in 2018 on Google, which has great impact in Vietnam"[10].

Through the empirical research on the dissemination and acceptance of Chinese films and TV dramas in Vietnam, it proves that even the audience follow the trend of TV series energetically, but only those works can make a deep impression on the hearts of the audience can induce deep acceptance. Only a small number of films and television works really obtain the ideal communication effect, and only they can let the audience remember for a long time.

\section{Make full use of online platforms to promote the dissemination of film and television in China}

According to our statistics of some video website that have the copyright in Vietnam, one of those has a large number of Chinese film and television works ranging from 300 to 400 . Chinese film copyright is often purchased by professional companies in Vietnam or Southeast Asia. These companies act as middlemen and resell to the website publisher. All of Vietnamese online distribution channels will buy distribution rights from the middleman, There are few cases of direct purchases from Chinese production companies, because of expensive exclusive royalties. Vietnamese network distributors will give priority to buy some production that have already been expected by the audience or discussed by the media, such as "The Story of Yanxi Palace”, "Legend of Ruyi”, "There is a Wooden Bridge in the South", "Secrets of the Three Kingdoms" and other works. In addition to TV stations' websites, Vietnam now has more than a dozen websites dedicated to broadcasting movies, dramas and reality show, most of them broadcast Chinese film and television works.

Recently more popular sites are ZingTV, PT Play, Netflix, iflix, Danet, Fim+, ClipTV and so on. These websites may belong to Chinese film release media company, or belong to foreign service companies that have entered the Vietnamese market recently. Such as 1flix, it is a website service provider in Malaysia, even it doesn't have as many movies as other sites, but it has more Chinese and South Korean TV dramas that is tailored to Vietnamese tastes. Except for paid-for film projection services, there are still many websites in Vietnam that are not approved by regulators. These websites' servers are the foreign, although they are constantly censored and shut down, new sites are popping up every day.

All of the above works were first broadcast on the Internet in Vietnam, after winning a good reputation, they are purchased by TV channels to broadcast. But Vietnamese television broadcast the series much later than they did in China, even they were a year or two after production. Vietnamese televisions have again attached importance to the broadcasting of Chinese TV dramas, especially those hot style big-budget dramas. A few years ago, Vietnam television usually broadcast Chinese dramas that are made in previous 
year or two. Some TV shows are purchased by TV stations only after they have been online for a long time and got a good reputation. But in these two years, Vietnamese TV stations have started distributing Chinese TV dramas simultaneously again, forming new competition with online platforms.

\section{Reasons for the popularity of IP drama in Vietnamese intercultural communication and its development countermeasures}

The critical reasons why Chinese films and TV programs are accepted by Vietnamese audiences, it reflects the universality of its values, and the expectation of the Vietnamese market on Chinese films and television. In terms of values, these years, the most accepted value of Chinese films by Vietnamese audiences is love, which is one of the enduring values of common concern to mankind. Although love is one of the core values of Chinese film and television, Vietnamese audience cares more about family, kindheartedness, moral values, which indicates Vietnamese audiences still concern on the Chinese local film and television genres that show real life, social ethics and so on, it can be seen that the unique position of Chinese film and television in the Vietnamese market has not changed, but these themes are not as important and actively explored as before. On the surface, Chinese films and TV shows seem to be remaking all previous genres. In fact, "in different periods of competition with the TV industry of other countries, Chinese film and television industry will choose a certain kind of theme as the leading product to develop and grow"[11]. In addition, the genre and style of Chinese films in each period are different from those of the United States, South Korea and other influential films and television products, the difference of Chinese film and television also make up for some of the shortcomings of overseas film and television market. Due to the influence of cultural differences, national conditions and various countries economic development, in the early 21st century, the phenomenon of "cultural discount" appeared in the overseas dissemination of Chinese films and TV programs, which also aroused the attention and thinking of the Chinese film and television circles.

In the process of cross-cultural communication, the first thing to do is to make sure that the audience knows the importance of the content, according to the situation of intercultural communication of Chinese film and television, the following three countermeasures are given in this paper:

(1)Focus on content selection. It is important to focus on empathy, and choose Chinese stories that international audiences can understand, and grasp the uniqueness of Chinese culture to make it an important advantage to attract international audiences.

(2)Improve narrative style. Concentrate on aesthetic differences between Chinese and foreign art forms, focus on the way of expression that is easy to be accepted by the international audience, and make Chinese stories more international.

(3)Combined with Chinese internationalization, make full use of the international Chinese language communication platform, and explore new ways of Chinese film and television cross-cultural diffusion.

\section{Conclusions}

Chinese President Xi Jinping stresses “ 'Ctelling China's story well' ”[12], to show a good national image, it is necessary to strengthen the construction of intercultural communication capacity, and link a good Chinese story with a good world story. As cultural export products in the international cultural market, film and television works are an opportunity 
for domestic and foreign people to understand China and Chinese culture. "The crosscultural diffusion of Chinese film and television has great value to the design of China's national image"[13].

In the era of the rise of network platforms and the process of film and television transmission, the development of TV channels and video websites in Vietnam is the direction of media integration. It has brought new development prospects for Chinese films and TV programs to enter Vietnam and the global market, to some extent. Vietnam has absorbed Eastern and Western cultures in the course of its historical development, it also adopted the cultural strategy of "integrating into the international community", in the new century. The dissemination and acceptance of Chinese film and television in Vietnam can enhance the mutual communication, mutual understanding and common development between Chinese and Vietnamese TV industries, which provides a practical basis for the foreign communication of Chinese film and television. In the context of intense international competition and changing tastes of the audience, Chinese film and television should continue to innovate in content and form, and try hard to disseminate Chinese IP series widely.

\section{References}

1. Dongmei Yang, The problem and way out of the spread of Chinese film and television culture under the view of cultural self - confidence. Journal of Jilin Engineering and Technology Normal College, 11,52-54. (2019)

2. Shirong Ruan, Research on the role of Chinese contemporary film and television in the teaching of Chinese in Vietnam, Guangxi University, MA thesis. (2011)

3. Guofang Qin, The advantages and enlightenments of IP film and television drama. Publish wide angle, 15,39-41. (2020)

4. Jinhua Pei, From the perspective of communication science to explore the hot phenomenon of IP drama - take "Dear, Love" as an example. Publishing wide-angle, 21,76-78. (2019)

5. Yu Wang. The research on the production of news-type TV news programs in China in the all - media era. Hunan University, MA thesis. (2016)

6. Ruixu Wang, New Media, New Youth, New Culture, Three Gorges University, MA thesis. (2019)

7. Wei Lin. Aesthetic thinking application of film and television post - production. The spread of science and technology, 21,63-64. (2017)

8. Qin Yaqi, Zhang Miaomiao, and Xu Wei, The IP transformation mode and its multidimensional communication path of china's popular TV dramas." Media and Art Studies, 02,34-39. (2019)

9. Kang Gao, From the interactive harmony between cultural discount and cultural valueadded, see how to tell a good Chinese story - take the TV series "Yan Ju", for example. Journal of Southwest National University (Humanities and Social Sciences Edition), 11,181-188. (2019)

10. Yangsha $\mathrm{Xu}$, The spread of Chinese TV dramas in Vietnam in the Internet age. Cultural soft power, 04,83-90. (2017)

11. Yang Liu, On cultural communication and China's national image shaping in the context of globalization. Journal of Changjiang Normal College, 02,98-100. (2014)

12. Xi Jinping, The decisive victory will build a well-off society in an all-round way and win the great victory of socialism with Chinese characteristics in the new era - a report 
at the 19th National Congress of the Communist Party of China. Theoretical learning, 12, 4-25. (2017)

13. Qiuheng Zhishi, Research on the current situation of direct investment by Chinese enterprises in Vietnam and countermeasures, Chongqing Polytechnic University, MA thesis. (2014) 